\title{
Pengaruh Sektor Tersier terhadap Pertumbuhan Ekonomi Kawasan Barat dan Timur Indonesia
}

\author{
(The Effect of the Tertiary Sector on Economic Growth in the Western and Eastern Regions of \\ Indonesia)
}

Pramudya Kusuma $^{1 *}$, Aisyah Fitri Yuniasih ${ }^{2}$

${ }^{1,2}$ Politeknik Statistika STIS

Jl. Otto Iskandardinata No.64C, RT.1/RW.4, Bidara Cina, Kecamatan Jatinegara, Kota Jakarta Timur, DKI Jakarta E-mail: 211709940@stis.ac.id

\begin{abstract}
ABSTRAK
Sektor tersier merupakan sektor lapangan usaha yang menghasilkan produk berupa jasa. Perubahan struktural ekonomi menuju sektor tersier telah terjadi di Indonesia. Peristiwa tersebut diduga memiliki pengaruh terhadap pertumbuhan ekonomi yang berbeda antara kawasan barat dan timur Indonesia. Penelitian ini bertujuan untuk menganalisis gambaran dan pengaruh sektor tersier terhadap pertumbuhan ekonomi pada Kawasan Barat Indonesia (KBI) dan Kawasan Timur Indonesia (KTI). Metode yang digunakan adalah analisis data panel Fixed Effects Model dengan estimasi Feasible Generalized Least Squares. Hasil penelitian menunjukkan bahwa pada KBI maupun KTI, sektor tersier yang dijelaskan oleh produktivitas tenaga kerja dan share tenaga kerja memiliki pengaruh positif terhadap pertumbuhan ekonomi, dengan pengaruh pada KBI lebih besar daripada KTI. Variabel lain yang digunakan yaitu belanja langsung pemerintah memiliki pengaruh positif terhadap pertumbuhan ekonomi serta laju pertumbuhan penduduk memiliki pengaruh negatif terhadap pertumbuhan ekonomi. Peningkatan produktivitas sektor tersier dan tenaga kerja sektor tersier dapat dilakukan sebagai upaya peningkatan pertumbuhan ekonomi.
\end{abstract}

Kata kunci: sektor tersier, pertumbuhan ekonomi, analisis data panel, KBI, KTI

\begin{abstract}
The tertiary sector is a sector that produces products in the form of services. Structural changes in the economy towards the tertiary sector have occurred in Indonesia. These events are thought to have had different effects on economic growth between the western and eastern regions of Indonesia. This study aims to analyze the description and effects of the tertiary sector on economic growth in western Indonesia (KBI) and eastern Indonesia (KTI). The method used is Fixed Effects Model panel data analysis with Feasible Generalized Least Squares estimation. The results showed that in KBI and KTI, the tertiary sector described by labor productivity and labor share had a positive effect on economic growth, with the effect on KBI being greater than KTI. Another variable used is direct government spending has a positive effect on economic growth and the rate of population growth has a negative effect on economic growth. Increasing the productivity of the tertiary sector and tertiary sector laborforce can be carried out as an effort to increase economic growth.
\end{abstract}

Keywords: tertiary sector, economic growth, panel data analysis, KBI, KTI

\section{PENDAHULUAN}

Peningkatan perekonomian merupakan salah satu tujuan utama yang ingin dicapai oleh setiap negara. Kondisi perekonomian yang semakin meningkat menunjukkan keberhasilan dari suatu negara dalam mengelola perekonomiannya. Kondisi perekonomian yang meningkat tersebut berperan penting dalam meningkatkan kesejahteraan masyarakat. Pentingnya pertumbuhan ekonomi dalam peningkatan kesejahteraan masyarakat mendorong pemerintah untuk berusaha meningkatkan pertumbuhan ekonomi di wilayahnya.

Pada tahun 2015, perekonomian Indonesia mengalami perlambatan dengan pertumbuhan ekonomi sebesar 4,88 persen. Pertumbuhan ekonomi Indonesia pada tahun 2018 merupakan pertumbuhan terbaik dalam 4 tahun terakhir dengan angka 5,17 persen, namun kondisi tersebut masih menjadi suatu masalah karena tidak mencapai target awal yang ditetapkan pemerintah yaitu sebesar 5,4 persen yang kemudian direvisi menjadi 5,2 persen. Pada tahun 2019, pertumbuhan ekonomi Indonesia turun menjadi 5,02 persen yang merupakan pertumbuhan ekonomi yang terendah selama 4 tahun terakhir. Salah satu permasalahan yang dihadapi oleh suatu negara terkait pertumbuhan ekonomi adalah masalah jebakan pendapatan kelas menengah (middle income trap). Untuk dapat keluar dari jebakan pendapatan kelas menengah tersebut diperlukan pertumbuhan ekonomi yang mencapai 6 hingga 7 persen, sementara jika mengandalkan fiskal dan 
moneter saja maka pertumbuhan ekonomi Indonesia diestimasi hanya berada disekitar 5 persen, terlihat dari pertumbuhan ekonomi tahun 2015 hingga 2019. Kondisi pertumbuhan ekonomi yang cenderung stagnan menyebabkan pemerintah perlu memikirkan rencana untuk tidak terjebak dalam pendapatan kelas menengah.

Analisis determinan pertumbuhan ekonomi telah menjadi subjek dalam banyak literatur. Beberapa penelitian menyatakan bahwa perubahan struktur produktif suatu perekonomian atau perubahan struktur ekonomi merupakan faktor penting dalam pertumbuhan ekonomi (Silva \& Teixeira, 2011). Mihnenoka dan Saulitis (2013) berpendapat bahwa pada jangka panjang kontribusi sektor primer dalam pertumbuhan ekonomi secara agregat menurun, sektor sekunder naik pada tahap awal kemudian menjadi konstan, dan sektor tersier proporsinya terus meningkat. Sektor tersier sebagai sektor yang berkembang pada tahap akhir perkembangan perekonomian dianggap menunjukkan kemajuan dari perekonomian suatu wilayah.

Sektor tersier atau yang dikenal juga dengan sektor jasa merupakan sektor lapangan usaha pada perekonomian yang menghasilkan produk berupa jasa atau produk tidak berwujud. Sektor tersebut mengandalkan kemampuan dan keterampilan yang dimiliki oleh manusia untuk menyediakan produk jasa. Sektor tersier dalam jangka panjang memberikan kontribusi terbesar pada perekonomian. Oleh karena itu, sektor tersier dijadikan faktor dalam menganalisis pertumbuhan ekonomi di suatu wilayah.

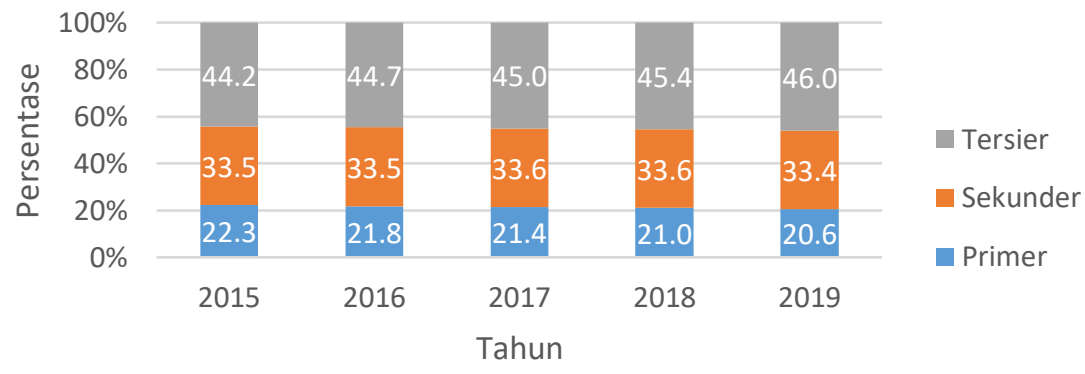

Sumber: BPS 2015-2019, diolah

Gambar 1. Share Nilai Tambah per Sektor Lapangan Usaha Indonesia 2015-2019.

Gambar 1 memperlihatkan bahwa sektor tersier mendominasi perekonomian Indonesia sejak tahun 2015 hingga tahun 2019. Share nilai tambah sektor tersier mengalami peningkatan, share nilai tambah sektor sekunder tetap serta share nilai tambah sektor primer mengalami penurunan. Kondisi ini mengindikasikan bahwa gejala deindustrialiasi di Indonesia semakin terlihat. Gejala deindustrialisasi ditandai dengan menurunnya output sektor primer, stagnasi pada sektor sekunder dan diikuti dengan peningkatan output sektor tersier pada struktur PDB suatu negara.

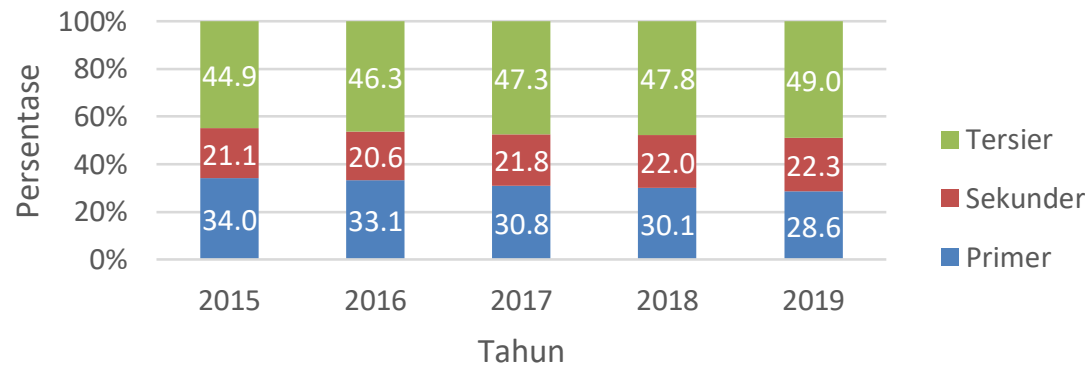

Sumber: BPS 2015-2019, diolah

Gambar 2. Share Tenaga Kerja per Sektor Lapangan Pekerjaan Indonesia 2015-2019.

Dilihat dari sisi tenaga kerja, sektor tersier telah menjadi sektor dengan jumlah tenaga kerja terbanyak serta memiliki pertumbuhan yang tinggi. Sektor sekunder meningkat namun memiliki pertumbuhan yang lebih rendah dibandingkan tersier, sementara sektor primer mengalami penurunan. Gambar 2 menunjukkan bahwa lapangan pekerjaan utama sektor tersier telah mendominasi lapangan pekerjaan utama tenaga kerja di Indonesia.

Berdasarkan kondisi pembangunan ekonomi, wilayah di Indonesia dapat dibagi menjadi dua kawasan yaitu Kawasan Barat Indonesia (KBI) dan Kawasan Timur Indonesia (KTI). Wilayah Jawa, Bali, Sumatera dan Kalimantan sebagai kawasan barat mendominasi PDB ADHK Indonesia pada tahun 2019 dengan kontribusi sebesar 89,9 persen. Sementara itu, wilayah Sulawesi, Nusa Tenggara, Maluku dan Papua hanya 
berkontribusi 10,1 persen dari total PDB ADHK Indonesia tahun 2019. Hal tersebut menunjukkan terjadi ketimpangan antara kawasan barat dan kawasan timur Indonesia. Oleh karena itu penelitian ini membedakan Kawasan Barat Indonesia (KBI) dan Kawasan Timur Indonesia (KTI) dalam menganalisis pengaruh sektor tersier terhadap pertumbuhan ekonomi.

Provinsi-provinsi di Indonesia, baik KBI dan KTI memiliki karakteristik yang beragam. Struktur ekonomi suatu wilayah dipengaruhi oleh potensi sumber daya yang berada pada wilayah tersebut. Menurut Lutskiv dan Habrel (2016), ketidakseimbangan struktur pada ekonomi di suatu wilayah terjadi karena adanya kekurangan pada faktor material, intelektual, finansial, sumber daya inovatif dan investasi, serta disebabkan juga oleh penurunan produksi yang inovatif. Penelitian ini menganalisis sektor tersier KBI dan KTI yang terlihat dari keragaman provinsi-provinsi pada kawasan tersebut pada periode yang ditentukan sehingga metode yang digunakan adalah analisis data panel.

Teixeira dan Queiros (2016) melakukan penelitian mengenai pengaruh human capital dan perubahan struktural yang dijelaskan oleh share tenaga kerja pada sektor "high-level" atau padat pengetahuan terhadap pertumbuhan ekonomi negara-negara anggota OECD tahun 1960-2011 dengan metode analisis regresi panel dinamis. Hasil penelitian menunjukkan bahwa human capital, perubahan struktural dan interaksinya berpengaruh positif terhadap pertumbuhan ekonomi. Mihnenoka dan Saulitis (2013) melakukan penelitian mengenai signifikansi perubahan struktur ekonomi negara Latvia yang terlihat dari laju pertumbuhan nilai tambah tiap-tiap sektor tahun 1991-2010 dengan metode regresi data time series. Hasil menunjukkan bahwa sektor tersier signifikan dan memberikan pengaruh positif terbesar dalam perekonomian Latvia. Wardhana, Kharisma, dan Lisdiyanti (2020) meneliti mengenai pengaruh teknologi informasi komunikasi terhadap pertumbuhan ekonomi pada wilayah barat dan timur Indonesia periode 2014-2018 dengan analisis data panel Fixed Effects Model Generalized Least Square. Hasil penelitian menunjukkan bahwa teknologi informasi dan komunikasi pada kawasan barat dan timur Indonesia signifikan meningkatkan pertumbuhan ekonomi dengan pengaruh pada kawasan barat lebih besar dari kawasan timur Indonesia.

Selain transfomasi struktual, faktor lain yang memengaruhi pertumbuhan ekonomi adalah pengeluaran pemerintah yang dapat didekati dengan belanja langsung pemerintah dan pertumbuhan penduduk. Pengeluaran pemerintah yang produktif memiliki korelasi positif dengan pertumbuhan ekonomi jangka panjang (Barro, 1990). Selain itu, pertumbuhan penduduk dalam Peterson (2017) dijelaskan memiliki peranan dalam pertumbuhan ekonomi.

Tujuan penelitian ini antara lain menganalisis gambaran umum perkembangan sektor tersier dalam hal produktivitas dan share tenaga kerja, belanja langsung pemerintah serta laju pertumbuhan penduduk yang diduga memengaruhi pertumbuhan ekonomi pada provinsi-provinsi di Kawasan Barat Indonesia dan Kawasan Timur Indonesia tahun 2015-2019, serta menganalisis pengaruh sektor tersier dalam hal produktivitas dan share tenaga kerja, belanja langsung pemerintah serta laju pertumbuhan penduduk terhadap pertumbuhan ekonomi di Kawasan Barat Indonesia dan Kawasan Timur Indonesia pada tahun 2015-2019.

Hipotesis penelitian yang ditetapkan dalam penelitian ini adalah sektor tersier yang terlihat dari produktivitas tenaga kerja dan share tenaga kerja diduga berpengaruh positif terhadap pertumbuhan ekonomi. Variabel lain yang digunakan seperti pengeluaran langsung pemerintah diduga berpengaruh positif terhadap pertumbuhan ekonomi serta laju pertumbuhan penduduk diduga berpengaruh negatif terhadap pertumbuhan ekonomi. Selain itu, pengaruh sektor tersier terhadap pertumbuhan ekonomi pada KBI diduga memiliki pengaruh lebih besar daripada KTI.

\section{METODE}

\section{Landasan Teori}

\section{Pertumbuhan Ekonomi}

Pertumbuhan ekonomi merupakan peningkatan produksi barang dan jasa dalam suatu perekonomian dari periode sebelumnya akibat dari beberapa determinan sehingga pendapatan domestik menjadi meningkat. Sukirno (2011) menyatakan bahwa pertumbuhan ekonomi dapat diartikan sebagai perkembangan kegiatan perekonomian yang menyebabkan produksi barang dan jasa dalam masyarakat bertambah sehingga kemakmuran masyarakat meningkat. Perekonomian dianggap mengalami pertumbuhan jika nilai riil barang dan jasa yang diproduksi atau nilai tambah riil yang diperoleh unit ekonomi lebih besar dari pada tahun sebelumnya.

Para ekonom dalam perkembangannya telah melakukan beberapa penelitian untuk menentukan faktorfaktor yang merupakan determinan dalam pertumbuhan ekonomi. Zagler (2009) menyebutkan bahwa 
pertumbuhan ekonomi yang terjadi di suatu negara didorong oleh peristiwa perubahan struktural. Pengenalan mode produksi yang baru memungkinkan alokasi sumber daya menjadi lebih efisien, serta inovasi dari produk yang dihasilkan akan meningkatkan nilai produksi. Peterson (2017) meyebutkan bahwa pertumbuhan penduduk merupakan faktor penting yang memengaruhi pertumbuhan ekonomi secara keseluruhan. Selain itu, Moral-Benito (2008) berdasarkan penelitian-penelitian mengenai pertumbuhan ekonomi juga mempertimbangkan variabel makroekonomi lain yaitu pengaruh pemerintah yang dijelaskan oleh pengeluaran pemerintah.

\section{Perubahan Struktural dan Sektor Tersier}

Teori perubahan struktural berfokus pada mekanisme di mana ekonomi yang belum berkembang mengubah struktur ekonomi domestik mereka dari penekanan berat pada sektor pertanian tradisional menjadi ekonomi manufaktur dan jasa yang lebih modern, lebih urban, dan lebih beragam secara industri (Todaro \& Smith, 2015). Proses perubahan struktur ekonomi yang ditandai ekspansi sektor jasa atau tersier disebut Tersierisasi. Ekspansi ini dikaitkan dengan meluasnya permintaan untuk jasa akibat peningkatan pendapatan dan peningkatan standar hidup masyarakat. Wolfe (1955) dalam Mihnenoka dan Sauilitis (2013) menyebutkan bahwa sektor tersier merupakan sektor yang mengandalkan keterampilan manusia dalam menyediakan produk jasa. Lapangan usaha yang termasuk ke dalam klasifikasi sektor tersier antara lain Perdagangan Besar dan Eceran, Reparasi Mobil dan Sepeda Motor; Transportasi dan Pergudangan; Penyediaan Akomodasi dan Makan Minum; Informasi dan Komunikasi; Jasa Keuangan dan Asuransi; Real Estate; Jasa Perusahaan; Administrasi Pemerintahan, Pertahanan dan Jaminan Sosial Wajib; Jasa Pendidikan; Jasa Kesehatan dan Kegiatan Sosial; dan Jasa lainnya.

Hubungan Share Tenaga Kerja Sektor Tersier dengan Pertumbuhan Ekonomi

Herrendorf, Rogerson, dan Valentinyi (2014) menyatakan bahwa peningkatan perekonomian dikaitkan dengan peningkatan share tenaga kerja sektor tersier dan penurunan share tenaga kerja sektor primer, sementara share tenaga kerja sektor sekunder meningkat pada level pembangunan yang rendah dan menurun pada level pembangunan yang tinggi. Mihnenoka dan Saulitis (2013) juga berpendapat bahwa dalam jangka panjang kontribusi sektor primer pada perekonomian secara agregat akan menurun, kontribusi sektor sekunder akan naik pada tahap awal pembangunan kemudian menjadi konstan, serta kontribusi sektor tersier akan terus meningkat. Sektor tersier merupakan sektor yang berkembang pada tahap akhir perkembangan perekonomian dan mendorong pertumbuhan ekonomi. Oleh karena itu, peningkatan share tenaga kerja sektor tersier mampu meningkatkan pertumbuhan ekonomi.

\section{Hubungan Produktivitas Sektor Tersier dengan Pertumbuhan Ekonomi}

Produktivitas sektor tersier yang tinggi dapat menjadi kunci pertumbuhan ekonomi seiring dengan meningkatnya share sektor tersier dalam perekonomian (Fukao dan Miyagawa, 2010). Produktivitas sektor tersier yang tinggi menunjukkan bahwa tenaga kerja lapangan usaha sektor tersier mampu menghasilkan produk jasa dengan lebih efisien dan bernilai tinggi. Oleh karena itu, peningkatan produktivitas sektor tersier mampu meningkatkan pertumbuhan ekonomi.

\section{Hubungan Belanja Langsung Pemerintah dengan Pertumbuhan Ekonomi}

Pengeluaran pemerintah berpengaruh terhadap pertumbuhan ekonomi. Cooray (2009) menyebutkan bahwa pengeluaran pemerintah mampu mendorong pembangunan ekonomi secara keseluruhan. Pengeluaran belanja modal pada belanja langsung pemerintah dapat menyediakan dan membangun infrastruktur yang mampu mendukung pembangunan ekonomi daerah. Hal tersebut sangat penting karena pihak swasta tidak ingin menyediakan fasilitas publik, sementara tanpa fasilitas publik tersebut pihak swasta tidak berminat untuk menanamkan modalnya. Selain itu, pengelolaan belanja barang dan jasa yang terkait langsung dengan pelaksanaan program pemerintah diharapkan dapat menggerakkan pasar dan menjawab tantangan untuk menjadi instrumen pembangunan. Oleh karena itu, peningkatan belanja langsung pemerintah mampu meningkatkan pertumbuhan ekonomi.

\section{Hubungan Laju Pertumbuhan Penduduk dengan Pertumbuhan Ekonomi}

Peterson (2017) menyatakan bahwa pada negara-negara berkembang, pertumbuhan penduduk yang cepat cenderung merugikan dalam jangka pendek dan menengah karena menyebabkan sejumlah besar anakanak menjadi tanggungan. Selain itu, dikemukakan juga bahwa pertumbuhan penduduk yang disebabkan oleh tingkat kesuburan yang tinggi, seperti yang sering terjadi di negara-negara berkembang, dapat mengurangi kesejahteraan umum. Oleh karena itu, peningkatan laju pertumbuhan penduduk diduga menurunkan pertumbuhan ekonomi.

Kawasan Barat Indonesia dan Kawasan Timur Indonesia

Wilayah di Indonesia dapat dibagi menjadi dua kawasan ketika membahas mengenai pembangunan di Indonesia, yaitu Kawasan Barat Indonesia (KBI) dan Kawasan Timur Indonesia (KTI). Kawasan Barat Indonesia identik dengan capaian pembangunan yang baik sementara Kawasan Timur Indonesia relatif 
tertinggal dibanding Kawasan Barat Indonesia. Kesenjangan pembangunan antara KBI dan KTI masih cukup lebar dan cenderung permanen. Ketimpangan yang terjadi pada KTI dibandingkan KBI disebabkan beberapa faktor, diantaranya terbatasnya infrastruktur dasar yang dapat menghambat arus investasi, rendahnya kualitas sumber daya manusia, buruknya konektivitas wilayah, serta kurangnya pelayanan dasar yang berimbas terhadap rendahnya kualitas hidup.

\section{Tersierisasi Antarwilayah}

Peristiwa tersierisasi pada negara berkembang terjadi lebih awal dibanding pada negara maju sehingga memungkinkan terjadinya "Spurious tertiarization" atau tersieriasi palsu (Gurbuz, 2011). Gurbuz menyoroti situasi negara-negara bagian utara (amerika utara, eropa barat dan asia timur) dibanding dengan negaranegara bagian selatan (afrika, amerika latin dan negara-negara berkembang di asia). Peristiwa tersierisasi pada negara-negara selatan terfokus pada sektor jasa intensif tenaga kerja yang banyak menyerap tenaga kerja dengan keterampilan rendah, sementara negara-negara utara terfokus pada sektor dengan teknologi tinggi yang membutuhkan modal manusia yang tinggi. Kondisi tersebut disebabkan beberapa faktor yaitu perkembangan teknologi serta permintaan terhadap sektor jasa yang meningkat akibat tingginya kesejahteraan masyarakat. Kesenjangan antara wilayah barat Indonesia yang tergolong maju dan wilayah timur Indonesia yang lebih tertinggal dari wilayah barat memungkinkan proses tersierisasi di kedua wilayah tersebut berbeda dan memiliki pengaruh yang berbeda pada pertumbuhan ekonomi.

Penelitian ini meneliti variabel-variabel yang mewakili sektor tersier terhadap pertumbuhan ekonomi di Indonesia.Variabel yang mewakili sektor tersier adalah produktivitas dan share tenaga kerja. Variabel lain yang digunakan dalam penelitian ini adalah pengeluaran belanja langsung pemerintah dan laju pertumbuhan penduduk. Metode analisis yang digunakan adalah analisis data panel.

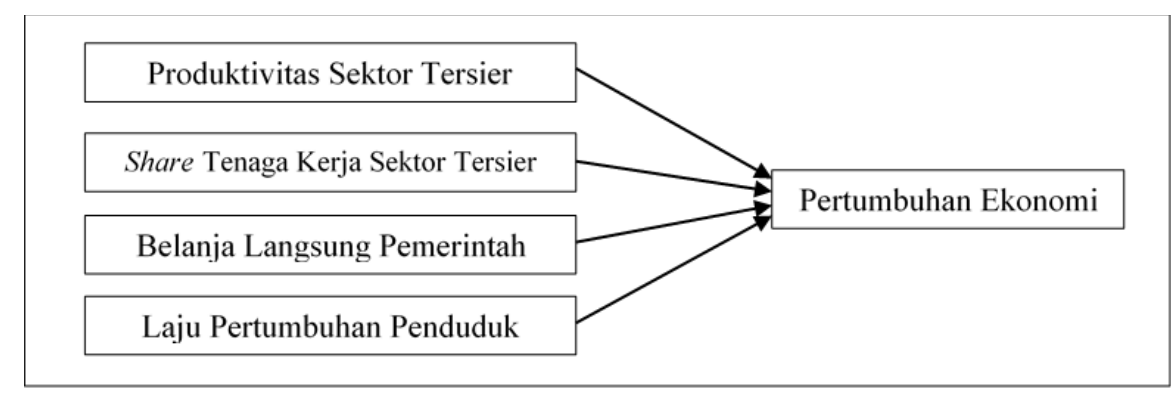

Gambar 4. Kerangka Pikir Penelitian.

\section{Data dan Sumber Data}

Tabel 1. Ringkasan Variabel Penelitian

\begin{tabular}{llll}
\hline Nama Variabel & Kode & Definisi & Sumber Data \\
\hline $\begin{array}{l}\text { Produk Domestik } \\
\text { Regional Bruto }\end{array}$ & PDRB & $\begin{array}{l}\text { Jumlah nilai tambah yang dihasilkan oleh seluruh unit usaha } \\
\text { dalam suatu daerah tertentu atas dasa harga konstan 2010 (miliar } \\
\text { rupiah) }\end{array}$ & $\begin{array}{l}\text { Badan Pusat } \\
\text { Statistik }\end{array}$ \\
$\begin{array}{l}\text { Produktivitas } \\
\text { Sektor Tersier }\end{array}$ & PST & $\begin{array}{l}\text { Nilai tambah sektor tersier per tenaga kerja sektor sektor tersier } \\
\text { atas dasar harga konstan 2010 (juta rupiah/tenaga kerja) }\end{array}$ & $\begin{array}{l}\text { Badan Pusat } \\
\text { Share Tenaga }\end{array}$ \\
$\begin{array}{l}\text { Kerja Sektor } \\
\text { Tersier }\end{array}$ & TKST & $\begin{array}{l}\text { Proporsi tenaga kerja sektor tersier per seluruh tenaga kerja } \\
\text { (persen) }\end{array}$ & Badan Pusat \\
$\begin{array}{l}\text { Belanja Langsung } \\
\begin{array}{l}\text { Pemerintah } \\
\text { Laju Pertumbuhan } \\
\text { Penduduk }\end{array}\end{array}$ & BLP & $\begin{array}{l}\text { Pengeluaran belanja langsung pemerintah daerah dalam realisasi } \\
\text { APBD (rupiah) }\end{array}$ & $\begin{array}{l}\text { Kementerian } \\
\text { Keuangan }\end{array}$ \\
\hline
\end{tabular}

Data yang digunakan dalam penelitian ini adalah data panel dengan cross section merupakan provinsiprovinsi yang ada di Indonesia dan time series merupakan periode waktu penelitian yang digunakan. Penelitian ini membagi provinsi-provinsi di Indonesia ke dalam dua model berdasarkan kawasan, yaitu Kawasan Barat Indonesia (KBI) dan Kawasan Timur Indonesia (KTI). Model KBI mencakup provinsiprovinsi di Pulau Sumatera, Jawa, Bali dan Kalimantan yang berjumlah 22 provinsi, sementara model KTI mencakup provinsi-provinsi di Sulawesi, Nusa Tenggara, Maluku dan Papua yang berjumlah 12 provinsi. Periode waktu yang digunakan dalam penelitian ini adalah tahunan dari 2015 hingga 2019, baik pada model 
KBI maupun KTI. Data yang digunakan merupakan data sekunder yang diperoleh dari Badan Pusat Statistik (BPS) dan Kementerian Keuangan. Variabel yang digunakan dijelaskan dalam tabel 1.

\section{Metode Analisis}

Analisis deskriptif yang digunakan dalam penelitian ini adalah analisis gambaran umum terkait variabel independen pada KBI dan KTI. Analisis deskriptif disajikan dalam bentuk tabel dan grafik. Analisis inferensia yang digunakan adalah analisis regresi data panel yang menganalisis pengaruh variabel sektor tersier yakni produktivitas sektor tersier dan share tenaga kerja sektor tersier serta pengeluaran belanja langsung pemerintah dan laju pertumbuhan penduduk terhadap pertumbuhan ekonomi. Model yang dibentuk berjumlah 2 model yang menjelaskan Kawasan Barat Indonesia dan Kawasan Timur Indonesia. Model terbaik yang digunakan baik pada KBI maupun KTI adalah Fixed Effects Model (FEM) dengan estimasi Feasible Generalized Least Squares (FGLS) untuk mengatasi masalah heteroskedastisitas dan korelasi crosssectional dari matriks varians-kovarians residual. Model penelitian ini dituliskan dengan bentuk persamaan:

$$
L N P D R B_{i t}=\alpha+\mu_{i}+\beta_{1} L N P S T_{i t}+\beta_{2} T K S T_{i t}+\beta_{3} L N B L P_{i t}+\beta_{4} P O P_{i t}+u_{i t}
$$

dimana:

$L N P D R B_{i t} \quad=$ logaritma natural PDRB provinsi ke-i periode ke-t

$L N P S T_{i t} \quad=$ logaritma natural produktivitas sektor tersier provinsi ke-i periode ke-t

$T_{K S T} \quad=$ share tenaga kerja sektor tersier provinsi ke-i periode ke-t

$L N B L P_{i t} \quad=$ logaritma natural belanja langsung pemerintah provinsi ke-i periode ke-t

$P O P_{i t} \quad=$ laju pertumbuhan penduduk provinsi ke-i periode ke-t

$\alpha \quad=$ konstanta

$\mu_{i} \quad=$ efek individu

$\beta_{1}, \beta_{2}, \beta_{3}, \beta_{4}=$ koefisien regresi

$u_{i t} \quad=$ komponen error

\section{HASIL DAN PEMBAHASAN}

\section{Gambaran Umum Variabel Independen KBI dan KTI Tahun 2015-2019}

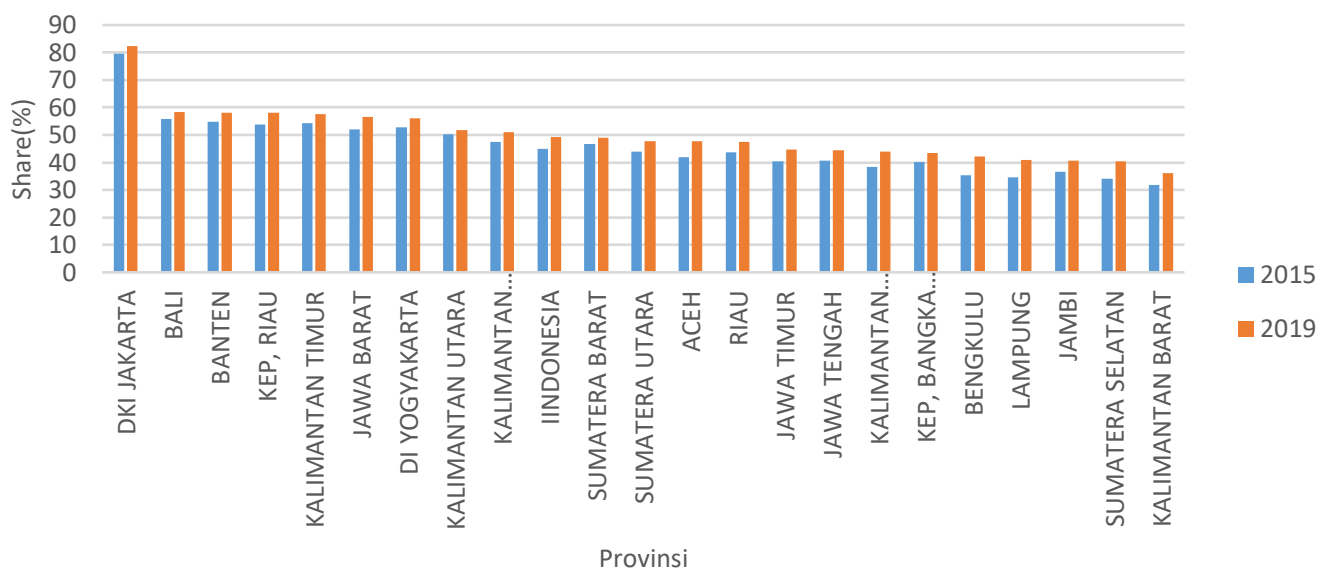

Sumber: BPS 2015 dan 2019, diolah

Gambar 5. Share Tenaga Kerja Sektor Tersier Provinsi di KBI Tahun 2015 dan 2019.

Gambar 5 menunjukkan bahwa Provinsi DKI Jakarta merupakan provinsi dengan share tenaga kerja sektor tersier tertinggi yaitu sebesar 79,46\% pada tahun 2015 dan $82,35 \%$ pada tahun 2019 , kemudian diikuti oleh provinsi Bali yaitu sebesar 55,73\% pada tahun 2015 dan 58,36\% pada tahun 2019 serta Provinsi Banten dengan 54,72\% pada tahun 2015 dan 58,13\% pada tahun 2019. Besarnya nilai share tenaga kerja sektor tersier pada provinsi-provinsi tersebut menunjukkan bahwa sektor tersier sudah menjadi tumpuan utama perekonomian provinsi-provinsi tersebut. Provinsi DKI Jakarta banyak menyerap tenaga kerja pada lapangan pekerjaan perdagangan serta real estate dan jasa jainnya, selain itu lapangan usaha akomodasi dan makan minum serta transportasi dan pergudangan juga memiliki share yang tinggi. Sementara itu, provinsi dengan share tenaga kerja sektor tersier terendah adalah Provinsi Kalimantan Barat dengan nilai share tenaga kerja sektor tersier tahun 2015 sebesar 31,68\% dan tahun 2019 sebesar 35,98\%. Tenaga kerja pada Provinsi Kalimantan Barat masih didominasi Lapangan Pekerjaan Utama sektor Pertanian. 
Seluruh provinsi di Kawasan Barat Indonesia mengalami peningkatan share tenaga kerja pada sektor tersier dari tahun 2015 hingga 2019. Provinsi Bengkulu merupakan provinsi dengan peningkatan share tenaga kerja sektor tersier tertinggi yakni sebesar $6,71 \%$. Peningkatan yang tinggi menunjukkan peralihan struktur ekonomi menuju sektor tersier ketika tenaga kerja mulai mengisi lapangan pekerjaan utama sektor tersier. Provinsi Bengkulu mengalami peningkatan tenaga kerja yang tinggi pada sektor jasa perusahaan.

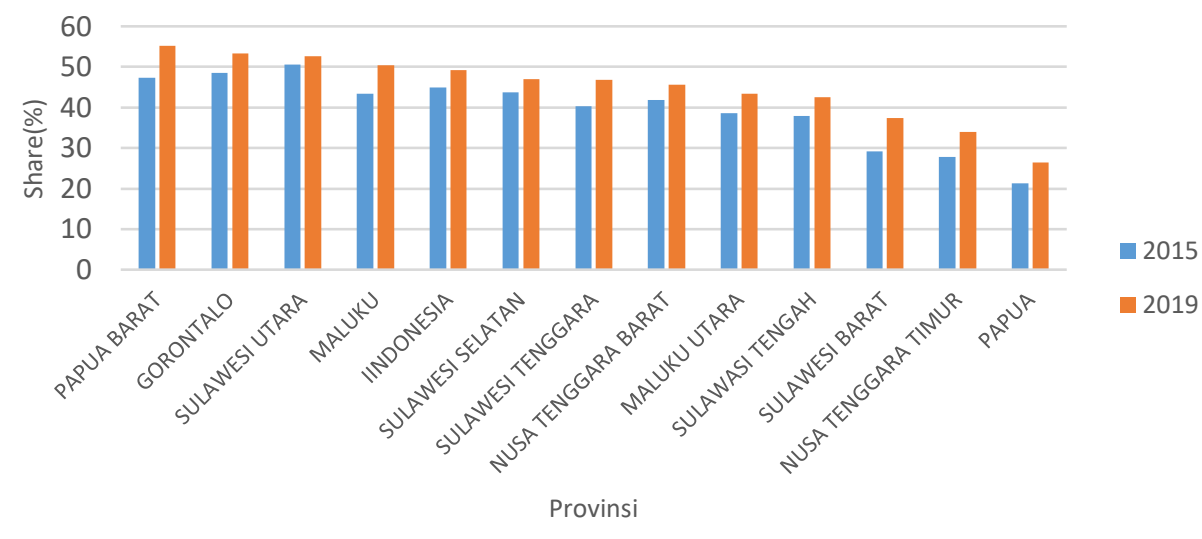

Sumber: BPS 2015 dan 2019, diolah

Gambar 6. Share Tenaga Kerja Sektor Tersier Provinsi di KTI Tahun 2015 dan 2019.

Gambar 6 memperlihatkan bahwa Provinsi Papua Barat merupakan provinsi dengan share tenaga kerja sektor tersier tertinggi pada tahun 2015 dan 2019 yaitu sebesar 47,35\% pada tahun 2015 dan 55,27\% pada tahun 2019, kemudian diikuti oleh provinsi Gorontalo dengan 48,54\% pada tahun 2015 dan 53,33\% pada tahun 2019 serta Provinsi Sulawesi Utara dengan 50,52\% pada tahun 2015 dan 52,57\% pada tahun 2019. Pada Provinsi Papua Barat, tenaga kerja mulai mengisi mengisi lapangan-lapangan pekerjaan utama yang tergolong sektor tersier seperti perdagangan; administrasi pemerintahan, pertahanan dan jaminan sosial wajib; serta transportasi dan pergudangan. Sementara itu, Provinsi Papua merupakan provinsi dengan share tenaga kerja sektor tersier yang terendah terendah yaitu sebesar 21,33\% pada tahun 2015 dan 26,39\% pada tahun 2019. Pada Provinsi Papua, mayoritas kabupaten terutama kabupaten tertinggal didominasi sektor pertanian sebagai lapangan pekerjaan utama tenaga kerjanya sementara sektor jasa terkonsentrasi di kabupaten dan kota yang tergolong maju.

Seluruh provinsi di Kawasan Timur Indonesia mengalami peningkatan share tenaga kerja sektor tersier dari tahun 2015 hingga 2019. Provinsi Sulawesi Barat merupakan provinsi dengan peningkatan share tenaga kerja sektor tersier tertinggi yaitu sebesar 8,28\%. Lapangan pekerjaan di Provinsi Sulawesi Barat masih didominasi oleh pertanian, namun pada wilayah perkotaan lapangan pekerjaan yang mendominasi adalah perdagangan dan jasa-jasa. Lapangan usaha tersebut juga mendominasi pada tenaga kerja berjenis kelamin perempuan.

Tabel 2. Ringkasan Statistik Produktivitas Sektor Tersier KBI dan KTI tahun 2015-2019 (juta rupiah/tenaga kerja).

\begin{tabular}{lllllll}
\hline Wilayah & Statistik & 2015 & 2016 & 2017 & 2018 & 2019 \\
\hline \multirow{4}{*}{ KBI } & Range & 240,1560 & 233,363 & 283,6923 & 286,3126 & 301,1470 \\
& Minimum & 43,0428 & 43,1157 & 45,8061 & 47,0079 & 47,4414 \\
& Maksimum & 283,1988 & 276,3520 & 329,4984 & 333,3205 & 348,5884 \\
& Rata-rata & 76,8757 & 74,1430 & 78,7063 & 80,1335 & 81,9106 \\
\hline \multirow{4}{*}{ KTI } & Range & 87,1410 & 65,3418 & 76,8958 & 69,9802 & 81,3862 \\
& Minimum & 39,9131 & 37,2886 & 41,2189 & 44,1080 & 40,7005 \\
& Maksimum & 127,0541 & 102,6303 & 118,1147 & 114,0882 & 122,0867 \\
& Rata-rata & 64,0402 & 58,8698 & 64,4123 & 65,6638 & 65,3875 \\
\hline
\end{tabular}

Sumber: BPS 2015-2019, diolah

Tabel 2 menunjukkan bahwa rata-rata produktivitas sektor tersier pada provinsi-provinsi di KBI dan KTI tahun 2015-2019. Rata-rata produktivitas sektor tersier KBI mengalami peningkatan meskipun sempat turun di tahun 2016 dengan yang tertinggi sepanjang tahun 2015 hingga 2019 dimiliki oleh Provinsi DKI Jakarta, sementara yang terendah dimiliki Provinsi Kalimantan Selatan pada tahun 2015 hingga 2016 dan 
Jawa Barat tahun 2017 hingga 2019. Rata-rata produktivitas sektor tersier KTI memiliki tren meningkat meskipun turun pada tahun 2016 dan 2019 dengan rata-rata tertinggi sepanjang tahun 2015 hingga 2019 dimiliki oleh Provinsi Papua, sementara rata-rata terendah dimiliki oleh Provinsi Nusa Tenggara Barat pada tahun 2015, 2017 hingga 2019 serta Gorontalo tahun 2016.

Tabel 3. Ringkasan Statistik Belanja Langsung Pemerintah KBI dan KTI tahun 2015-2019 (miliar rupiah).

\begin{tabular}{lllllll}
\hline Wilayah & Statistik & 2015 & 2016 & 2017 & 2018 & 2019 \\
\hline \multirow{4}{*}{ KBI } & Range & 20088,7429 & 21174,9602 & 25481,8174 & 30034,2191 & 32516,1911 \\
& Minimum & 789,0939 & 853,1806 & 885,6457 & 1004,1693 & 1143,1177 \\
& Maksimum & 20877,8368 & 22028,1408 & 26367,4631 & 31038,3885 & 33659,3088 \\
& Rata-rata & 3426,5342 & 3488,4544 & 4092,0558 & 4433,6253 & 4968,6627 \\
\hline \multirow{4}{*}{ KTI } & Range & 4642,6167 & 4206,3751 & 4720,6918 & 3717,0194 & 5617,5144 \\
& Minimum & 773,6425 & 743,9149 & 719,4798 & 694,8714 & 895,3002 \\
& Maksimum & 5416,2592 & 4950,2900 & 5440,1716 & 4411,8909 & 6512,8145 \\
& Rata-rata & 1719,4409 & 1755,9418 & 1878,3480 & 1810,2461 & 2243,0012 \\
\hline
\end{tabular}

Sumber: Kemenkeu 2015-2019, diolah

Tabel 3 menunjukkan bahwa rata-rata belanja langsung pemerintah provinsi-provinsi di KBI dan KTI tahun 2015-2019. Rata-rata belanja langsung pemerintah KBI mengalami peningkatan dari tahun 2015 hingga tahun 2019. Provinsi DKI Jakarta merupakan provinsi dengan belanja langsung pemerintah tertinggi sementara Provinsi Kep. Bangka Belitung merupakan provinsi dengan belanja langsung pemerintah terendah. Rata-rata belanja langsung pemerintah KTI memiliki tren positif meskipun sempat turun di tahun 2018. Provinsi Papua merupakan provinsi dengan belanja langsung pemerintah tertinggi sementara Provinsi Gorontalo merupakan provinsi dengan belanja langsung pemerintah terendah.

Tabel 4. Ringkasan Statistik Laju Pertumbuhan Penduduk KBI dan KTI tahun 2015-2019 (persen)

\begin{tabular}{lllllll}
\hline Wilayah & Statistik & 2015 & 2016 & 2017 & 2018 & 2019 \\
\hline \multirow{4}{*}{ KBI } & Range & 3,8020 & 2,5073 & 2,5154 & 2,5087 & 2,5076 \\
& Minimum & 0,4509 & 0,6448 & 0,6186 & 0,5917 & 0,5640 \\
& Maksimum & 4,2529 & 3,1521 & 3,1340 & 3,1004 & 3,0715 \\
& Rata-rata & 1,8147 & 1,4099 & 1,3718 & 1,3344 & 1,2963 \\
\hline \multirow{4}{*}{ KTI } & Range & 2,1152 & 1,5527 & 1,5472 & 1,5492 & 1,5620 \\
& Minimum & 0,9679 & 0,9131 & 0,8815 & 0,8436 & 0,7962 \\
& Maksimum & 3,0831 & 2,4658 & 2,4287 & 2,3929 & 2,3582 \\
& Rata-rata & 1,8566 & 1,4418 & 1,4027 & 1,3651 & 1,3288 \\
\hline
\end{tabular}

Sumber: BPS 2015-2019, diolah

Tabel 4 menunjukkan bahwa rata-rata laju pertumbuhan penduduk provinsi-provinsi di KBI dan KTI tahun 2015-2019. Rata-rata laju pertumbuhan penduduk KBI mengalami penurunan dari tahun 2015 hingga tahun 2019. Laju pertumbuhan penduduk terendah dimiliki Provinsi Jawa Timur pada tahun 2015 dan 2019 serta Provinsi Jawa Tengah pada tahun 2016 hingga 2018, sementara Provinsi Kep. Riau merupakan provinsi dengan laju pertumbuhan penduduk tertinggi. Rata-rata laju pertumbuhan penduduk di KTI mengalami penurunan dari tahun 2015 hingga 2019. Laju pertumbuhan penduduk terendah dimiliki Provinsi Sulawesi Utara pada tahun 2015, 2018 dan 2019 serta Sulawesi Selatan pada tahun 2016 dan2017. Sementara itu, Provinsi Papua Barat merupakan provinsi dengan laju pertumbuhan tertinggi. 


\section{Pengaruh Variabel Independen terhadap Pertumbuhan Ekonomi KBI dan KTI Tahun 2015-2019}

Tabel 5. Ringkasan model Kawasan Barat Indonesia dan Kawasan Timur Indonesia FEM FGLS

\begin{tabular}{|c|c|c|c|c|}
\hline \multirow[t]{2}{*}{ Variabel } & \multicolumn{2}{|c|}{ Kawasan Barat Indonesia** } & \multicolumn{2}{|c|}{ Kawasan Timur Indonesia** } \\
\hline & Koefisien & $P$-value & Koefisien & P-value \\
\hline Intercep & $\begin{array}{l}5,796433^{*} \\
(0,276473)\end{array}$ & 0,0000 & $\begin{array}{l}4,744437 * \\
(1,012123)\end{array}$ & 0,0000 \\
\hline LNPST & $\begin{array}{l}0,823405^{*} \\
(0,048547)\end{array}$ & 0,0000 & $\begin{array}{l}0,803798^{*} \\
(0,128517)\end{array}$ & 0,0000 \\
\hline TKST & $\begin{array}{l}0,025795^{*} \\
(0,001588)\end{array}$ & 0,0000 & $\begin{array}{l}0,022044 * \\
(0,003214)\end{array}$ & 0,0000 \\
\hline LNBLP & $\begin{array}{l}0,064940 * \\
(0,009380)\end{array}$ & 0,0000 & $\begin{array}{l}0,078932 * \\
(0,030984)\end{array}$ & 0,0072 \\
\hline POP & $\begin{array}{l}-0,047607 * \\
(0,009797)\end{array}$ & 0,0000 & $\begin{array}{l}-0,091582^{*} \\
(0,034837)\end{array}$ & 0,0059 \\
\hline $\mathrm{R}$-Squared & 0,999848 & & 0,998625 & \\
\hline Adj. $R$-Squared & 0,999803 & & 0,998156 & \\
\hline F-Statistic & 22092,07 & & 2130,667 & \\
\hline P-value (F-Statistic) & 0,000000 & & 0,000000 & \\
\hline $\begin{array}{l}\text { Variabel Dependen : } \\
\text { *signifikan pada tara } \\
\text { **memenuhi asumsi }\end{array}$ & $\begin{array}{l}\text { RB } \\
\text { fikansi } 5 \% \\
\text { litas dan non }\end{array}$ & ieritas & & \\
\hline
\end{tabular}

\section{Pengaruh Produktivitas Sektor Tersier Terhadap Pertumbuhan Ekonomi KBI dan KTI}

Pada KBI, produktivitas sektor sektor tersier berpengaruh positif terhadap PDRB. Peningkatan produktivitas sektor tersier sebesar 1 persen akan meningkatkan PDRB sebesar 0,8234 persen dengan asumsi variabel lain konstan. Pada KTI, produktivitas sektor tersier berpengaruh positif terhadap PDRB. Peningkatan produktivitas sektor tersier sebesar 1 persen akan meningkatkan PDRB sebesar 0,8038 persen dengan asumsi variabel lain konstan. Temuan ini sejalan dengan penelitian Lee dan McKibbin (2018). Peningkatan produktivitas sektor tersier dapat menjadi kunci untuk pertumbuhan ekonomi seiring dengan meningkatnya share sektor tersier. Koefisien pada KBI lebih besar daripada KTI menunjukkan bahwa pengaruh yang diberikan produktivitas sektor tersier terhadap pertumbuhan ekonomi pada KBI lebih besar daripada pengaruh produktivitas sektor tersier terhadap pertumbuhan ekonomi pada KTI.

\section{Pengaruh Share Tenaga Kerja Sektor Tersier Terhadap Pertumbuhan Ekonomi KBI dan KTI}

Pada KBI, share tenaga kerja sektor tersier berpengaruh positif terhadap PDRB. Peningkatan share tenaga kerja sektor tersier sebesar 1 satuan (persen) akan meningkatkan PDRB sebesar $0,025795^{*} 100=$ 2,5795 persen dengan asumsi variabel lain konstan. Pada KTI, share tenaga kerja sektor tersier juga berpengaruh positif terhadap PDRB. Peningkatan share tenaga kerja sektor tersier sebesar 1 satuan (persen) akan meningkatkan PDRB sebesar $0,022044 * 100=2,2044$ persen dengan asumsi variabel lain konstan. Temuan ini sejalan dengan hasil penelitian Teixeira dan Queirós (2016). Koefisien pada KBI lebih besar daripada KTI menunjukkan bahwa pengaruh share tenaga kerja sektor tersier terhadap pertumbuhan ekonomi pada KBI lebih besar daripada pengaruh share tenaga kerja sektor tersier terhadap pertumbuhan ekonomi pada KTI.

Pengaruh Belanja Langsung Pemerintah Terhadap Pertumbuhan Ekonomi KBI dan KTI

Pada KBI, belanja langsung pemerintah berpengaruh positif terhadap PDRB. Peningkatan pengeluaran belanja langsung pemerintah 1 persen akan meningkatkan PDRB sebesar 0,0649 persen dengan asumsi variabel lain konstan. Pada KTI, belanja langsung pemerintah berpengaruh positif terhadap PDRB. Peningkatan pengeluaran belanja langsung pemerintah 1 persen akan meningkatkan PDRB sebesar 0,0789 persen dengan asumsi variabel lain konstan. Temuan ini sejalan dengan penelitian Ichvani dan Sasana (2019). Koefisien pada KTI lebih besar daripada KBI menunjukkan bahwa pengaruh yang diberikan belanja langsung pemerintah terhadap pertumbuhan ekonomi pada KTI lebih besar daripada KBI.

Pengaruh Laju Pertumbuhan Penduduk Terhadap Pertumbuhan Ekonomi KBI dan KTI

Pada KBI, laju pertumbuhan penduduk berpengaruh negatif terhadap PDRB. Peningkatan laju pertumbuhan penduduk 1 satuan (persen) akan menurunkan PDRB sebesar 0,047607*100 $=4,7607$ persen dengan asumsi variabel lain konstan. Pada KTI, laju pertumbuhan penduduk berpengaruh negatif terhadap PDRB. Peningkatan laju pertumbuhan penduduk 1 persen akan menurunkan PDRB sebesar $0,091582 * 100=$ 9,1582 persen dengan asumsi variabel lain konstan. Temuan ini sejalan dengan penelitian Astuti, Hidayat dan Darwin (2017). Provinsi-provinsi dengan PDRB yang tinggi merupakan provinsi yang memiliki laju 
pertumbuhan penduduk yang rendah. Pertambahan penduduk seperti kelahiran akan meningkatkan jumlah penduduk usia tidak produktif dan meningkatkan rasio ketergantungan.

\section{KESIMPULAN}

Dalam analisis gambaran umum, sektor tersier yang terlihat dari produktivitas tenaga kerja dan share tenaga kerja mengalami peningkatan dari tahun 2015 hingga 2019 pada provinsi-provinsi di KBI maupun KTI. Selain itu, belanja langsung pemerintah pada provinsi-provinsi di KBI maupun KTI juga mengalami peningkatan sementara laju pertumbuhan penduduk pada provinsi-provinsi di KBI maupun KTI mengalami penurunan. Dalam analisis pengaruh variabel independen terhadap pertumbuhan ekonomi, sektor tersier yang dijelaskan oleh produktivitas tenaga kerja dan share tenaga kerja berpengaruh positif terhadap pertumbuhan ekonomi yang dijelaskan melalui PDRB, dengan pengaruh pada KBI lebih besar daripada KTI. Selain itu, belanja langsung pemerintah pada KBI dan KTI juga berpengaruh positif terhadap pertumbuhan ekonomi sementara laju pertumbuhan penduduk berpengaruh negatif terhadap pertumbuhan ekonomi.

\section{DAFTAR PUSTAKA}

Astuti, W. A., Hidayat, M., \& Darwin, R. (2017). Pengaruh Investasi, Tenaga Kerja dan Pertumbuhan Penduduk Terhadap Pertumbuhan Ekonomi di Kabupaten Pelalawan. Jurnal Akuntansi Dan Ekonomika. Jurnal Akuntansi dan Ekonomika, 7(2), 140-147.

Barro, R. J. (1990). Government Spending in a Simple Model of Endogeneous Growth. Journal of Political Economy, 98(5, Part 2), S103-S125.

Cooray, A. (2009). Government Expenditure, Governance and Economic Growth. Comparative Economic Studies, 51(3), 401-418.

Fukao, K., \& Miyagawa, T. (2010). Service Sector Productivity in Japan: The Key to Future Economic Growth. Korea Development Institute Conference.

Gurbuz, A. A. (2011). Comparing Trajectories of Structural Change. Cambridge Journal of Economics, 35, 1061-1085.

Herrendorf, B., Rogerson, R., \& Valentinyi, A. (2014). Chapter 6 - Growth and Structural Transformation. (P. Aghion, \& S. N. Durlauf, Penyunt.) Handbook of Economic Growth, 2, 855-941.

Ichvani, L. F., \& Sasana, H. (2019). Pengaruh Korupsi, Konsumsi, Pengeluaran Pemerintah dan Keterbukaan Perdagangan terhadap Pertumbuhan Ekonomi di ASEAN-5. Jurnal REP (Riset Ekonomi Pembangunan), 4(1), 61-72.

Lee, J. W., \& McKibbin, W. J. (2018). Service Sector Productivity and Economic Growth in Asia. Economic Modelling, 74, 247-263.

Lutskiv, O. M., \& Habrel, M. S. (2016). Regional Economic Development: Dynamics and Intensity of Changes. Economic Processes Management: International Scientific e-Journal.

Mihnenoka, A., \& Saulitis, J. (2013). Evaluating the Significance of Structural Changes within National Economy for Economic Growth of Latvia using the Econometric Model. Economics \& Business, 23(9), 62-70.

Moral-Benito, E. (2008). Determinants of Economic Growth: A Bayesian Panel Data Approach. Social Science Research Network.

Peterson, E. W. (2017). The Role of Population in Economic Growth. SAGE Open, 7(4).

Silva, E. G., \& Teixeira, A. A. (2011). Does Structure Influence Growth? A Panel Data Econometric Assessment of "Relatively Less Developed" Countries, 1979-2003. Industrial and Corporate Change, 20(2), 457-510.

Sukirno, S. (2011). Makro Ekonomi Teori Pengantar Edisi Ketiga. Jakarta: Rajawali Pers.

Teixeira, A. A., \& Queiros, A. S. (2016). Economic Growth, Human Capital and Structural Change: A Dynamic Panel Data Analysis. Research Policy, 45(8), 1636-1648.

Todaro, M. P., \& Smith, S. C. (2015). Economic Development. Pearson.

Wardhana, A., Kharisma, B., \& Lisdiyanti, T. (2020). Teknologi Informasi Komunikasi dan Pertumbuhan Ekonomi Wilayah Barat dan Timur Indonesia Periode 2014-2018. E-Jurnal Ekonomi Dan Bisnis Universitas Udayana, 9(11), 1103-1116.

Wolfe, M. (1955). The Concept of Economic Sectors. The Quarterly Journal of Economics, 69(3), 402-420.

Zagler, M. (2009). Economic Growth, Structural Change, and Search Unemployment. Journal of Economics, 96(1), 63-78. 